\title{
Una regla de predicción clínica identifica a aquellos pacientes que necesitan radiografías después de un traumatismo cervical cerrado
}

Validity of a set of clinical criteria to rule out injury to the cervical spine in patients with blunt trauma. Hoffman JR, Mower WR, Wolfson AB y cols. New Engl J Med. 2000;343:94-9.

\section{Objetivo}

Validar y comprobar la hipótesis que pacientes con traumatismo cervical cerrado que cumplen una regla clínica compuesta por cinco criterios tienen muy baja probabilidad de lesión cervical clínicamente importante, siendo innecesario realizar estudios de imágenes.

\section{Diseño}

Estudio prospectivo, multicéntrico y observacional.

Lugar

21 centros en EE.UU. de distintas características y complejidad.

\section{Pacientes}

Fueron incluidos 34069 pacientes con traumatismo cervical cerrado y estudios radiográficos en su evaluación inicial por guardia. No se incluyeron pacientes con traumatismos penetrantes o que realizaron radiografías por otra causa.

\section{Evaluación de factores pronósticos}

La regla clínica a evaluar incluyó los siguientes criterios: 1- Ausencia de dolor en la línea media y posterior de la columna cervical, 2- Ausencia de foco neurológico deficitario, 3- Estado de conciencia normal, 4- Sin evidencia de intoxicación y 5-Ausencia de otra lesión dolorosa que pueda ser foco de distracción del dolor cervical. Se consideraba positiva ante la presencia de cualquiera de estos factores, y negativa ante la ausencia de todos.

Todas las radiografías fueron analizadas por médicos radiólogos designados en cada centro ciegos a los datos clínicos. Las lesiones se clasificaron como clínicamente importantes o no importantes según requieran tratamiento específico o si su omisión no conlleva riesgo para el paciente respectivamente.

\section{Medición de resultados principales}

Se evaluó la utilidad de la regla de predicción clínica en 34069 pacientes con traumatismo cervical cerrado a los que se les realizaron radiografías.

\section{Resultados principales}

La regla de predicción clínica no identificó sólo 8 de los 818 pacientes que tuvieron lesión cervical (sensibilidad* 99\%; IC95\%: $98 \%$ a $99.6 \%$ ). El valor predictivo negativo* fue de $99.8 \%$ (IC95\%: $99.6 \%$ a $100 \%$ ). La especificidad* fue del $12.9 \%$ y el valor predictivo positivo* del $2.7 \%$. Sólo dos de los pacientes clasificados como de muy baja probabilidad de lesión tuvieron lesiones clínicamente importantes a las radiografías (sensibilidad 99.6\%; IC95\%: $98.6 \%$ a $100 \%$ ). Sólo uno de estos dos pacientes requirió cirugía. De acuerdo a estos resultados se pudo haber evitado realizar radiografías en 4309 de los 34069 casos (12.6\%) con la disminución de exposición a las radiaciones para el paciente y el importante ahorro de recursos que esto implicaría para el sistema de salud.

\begin{tabular}{|c|c|c|}
\hline Regla olínica & $\begin{array}{l}\text { Lesión radiográfica } \\
\text { presente }\end{array}$ & $\begin{array}{l}\text { Lesión radiográfica } \\
\text { ausente }\end{array}$ \\
\hline Positiva (probabilidad de lesión) & 810 & 28950 \\
\hline Negativa (baja probabilidad de lesión) & 8 & 4301 \\
\hline Regla clinica & $\begin{array}{l}\text { Lesión radiográfica } \\
\text { presente clínicamente } \\
\text { importante }\end{array}$ & $\begin{array}{l}\text { Lesión radiográfica } \\
\text { ausente clínicamente } \\
\text { importante }\end{array}$ \\
\hline Positiva (probabilidad de lesión) & 576 & 29184 \\
\hline Negativa (baja probabilidad de lesión) & 2 & 4307 \\
\hline
\end{tabular}

\section{Conclusiones}

Una regla clínica de simple aplicación puede ayudar al médico de guardia a identificar en forma confiable los pacientes que necesitan radiografías luego de un traumatismo cervical cerrado. La aplicación de esta regla podría reducir la utilización de radiografías en algunos de estos pacientes.

Fuente de financiamiento: Agency for Healthcare Research and Quality, EE.UU.

\section{Comentario}

El temor de pasar por alto el diagnóstico de lesión cervical en pacientes con traumatismo cerrado de esta región lleva generalmente a los médicos de guardia a solicitar radiografías prácticamente de rutina. Los cinco criterios clínicos que utilizan los autores para identificar los pacientes que necesitan realmente radiografías son de fácil aplicación y demostraron previamente tener una buena reproducibilidad interobservador* ${ }^{*}$. Si bien habían demostrado tener un buen valor predictivo negativo* la sensibilidad de estos criterios era escasa como para justificar un empleo masivo en forma confiable ${ }^{2}$. Este estudio prospectivo, multicéntrico y observacional cumple con el objetivo de validar la utilidad de esta regla de aplicación clínica. Menos de 1 en 4000 pacientes no fue diagnosticado y tuvo lesiones cervicales. Sólo dos de estas lesiones resultaron de importancia clínica. Solamente uno de estos pacientes requirió cirugía y retrospectivamente se vió que en realidad la regla de predicción clínica había sido mal empleada. La sensibilidad de esta regla para predecir una lesión clínicamente importante en la columna cervical fue $99.6 \%$. La aplicación de esta regla traería como consecuencia una menor exposición del paciente a radiaciones y una reducción de los costos del sistema de salud. En este estudio el $12.6 \%$ de las radiografías pudieron haber sido evitadas y aunque parezca una cifra menor el impacto clínico y económico se potenciaría si tomamos en cuenta todos los traumatismos cervicales de una población más numerosa (ciudad, país, etc.). Por último cabe destacar que como toda regla clínica y de valor predictivo su utilización debe ser una herramienta más entre las que cuenta el médico para realizar un diagnóstico. Su aplicación debe ser realizada con sumo cuidado, con conocimiento de las probables patologías cervicales traumáticas y aún así no debe reemplazar el juicio clínico en su totalidad en la evaluación individual de cada paciente.

Conclusiones del Comentador: Aunque la regla no ha sido validada en nuestros países, y no reemplaza el juicio clínico, parece razonable su utilización en la guardia. Si el resultado es negativo, se podría evitar la solicitud de radiografías.

Dr. Fernando M. Comba [ Jefe de Residentes. Instituto de Ortopedia y Traumatología "Carlos E. Ottolenghi". Hospital Italiano de Buenos Aires ]

\section{Referencias}

1- Mahadevan S, Mower WR, Hoffman JR et al. Interrater reliability of cervical spine injury criteria in patients with blunt trauma. Ann Emerg Med 1998;31:197-201.

2- Hoffman JR, Schriger DL, Mower WR et al. Low risk criteria for cervical-spine radiography in blunt trauma : a prospective study. Ann Emerg Med 1992; 12: 1454 1460 